\title{
EFFICACY OF HIGHER TEMPERATURE CRYOTHERAPY
}

\author{
J. Stübner, M. Bergling, M. Jontell, J. Walladbegi
}

Department of Oral Medicine and Pathology, Institute of Odontology, The Sahlgrenska Academy, University of Gothenburg, Gothenburg, Sweden

\section{Background}

Ice chips have effectively been used to alleviate the onset and duration of chemotherapy-induced oral mucositis (OM). However, although effective, this preventive measure entails discomfort such as shooting pain in the teeth. The aims of this study were to investigate the efficacy and tolerability profile of a novel intraoral cooling device (ICD) (Fig. 1), employing higher cooling temperatures than those provided by ice $(+$ $\left.0.5^{\circ} \mathrm{C}\right)$.

Figure 1

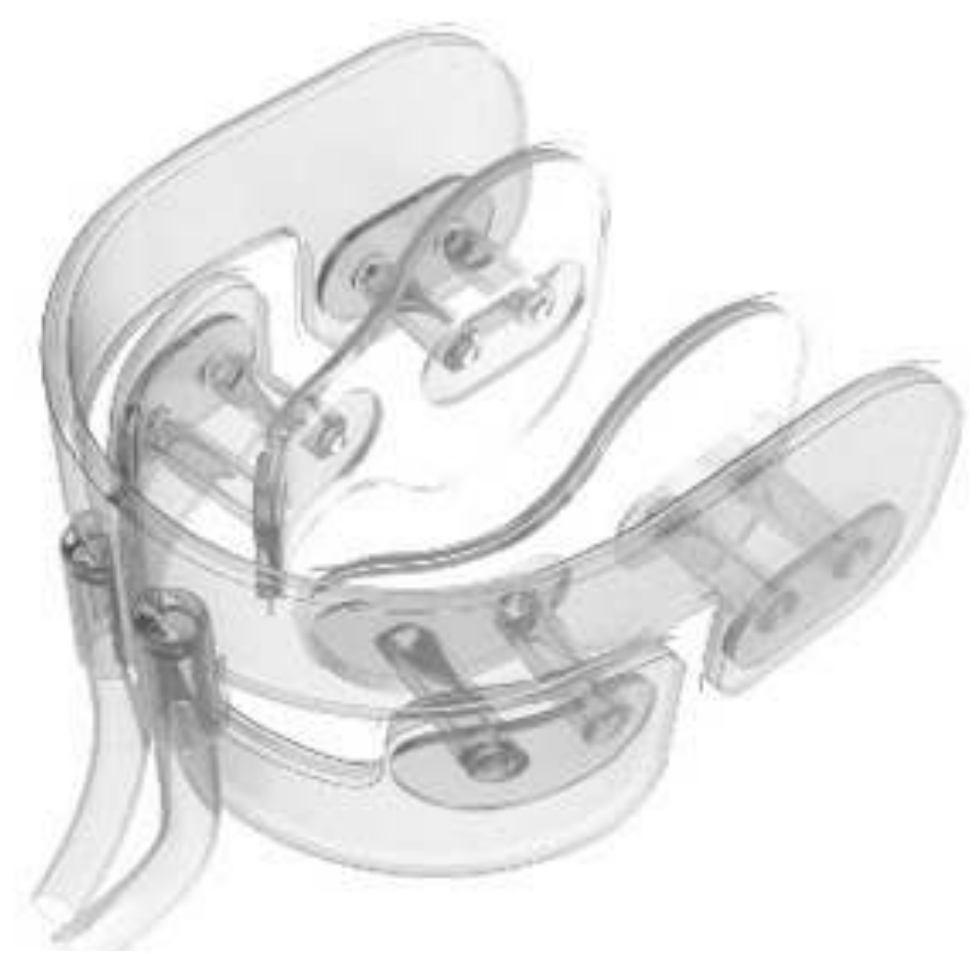

\section{Results}

The statistical analysis showed a significantly greater temperature reduction using $8^{\circ} \mathrm{C}$ compared to $15^{\circ} \mathrm{C}$, following both 30 - and 60 minutes $\left(1.9^{\circ} \mathrm{C}, p<.001\right)$ and $\left(2.5^{\circ} \mathrm{C}, p<.001\right)$ (Fig. 2). In contrast, cooling with $15^{\circ} \mathrm{C}$ was better tolerated and preferred over $8^{\circ} \mathrm{C}$ by 15 out of 20 participants $(p<.001)$.

\section{Subjects and methods}

In total, 20 healthy volunteers were enrolled in this randomized crossover study. Intraoral temperatures were registered, using an IRcamera, at baseline and following 30- and 60 minutes of cooling with the ICD, set to $8^{\circ} \mathrm{C}$ or $15^{\circ} \mathrm{C}$, respectively. Following each cooling session, tolerability was assessed using a questionnaire.

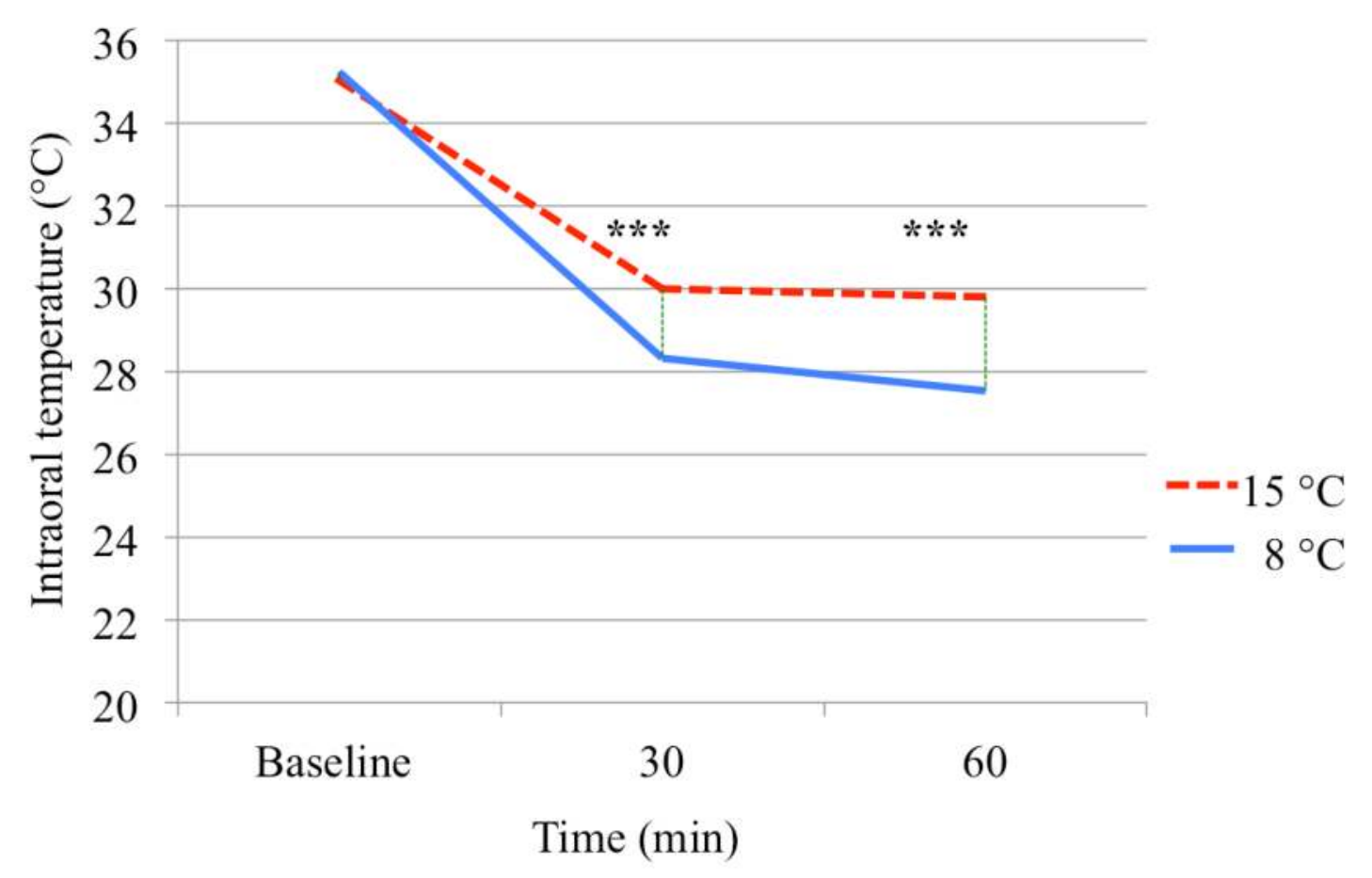

Figure 2

\section{Conclusions}

Intraoral cooling using a temperature of $15^{\circ} \mathrm{C}$ is better tolerated than $8^{\circ} \mathrm{C}$ but displays inferior capacity in temperature reduction of the oral mucosa. However, to elucidate whether this discrepancy of approximately $2^{\circ} \mathrm{C}$ is of clinical importance, the optimal temperature for prevention of OM needs to be identified. 